\title{
KLASIFIKASI HASIL CITRA MRI OTAK UNTUK MEMPREDIKSI JENIS TUMOR OTAK DENGAN METODE IMAGE THRESHOLD DAN GLCM MENGGUNAKAN ALGORITMA K-NN (NEAREST NEIGHBOR) CLASSIFIER BERBASIS WEB
}

\author{
Jajang Sofian ${ }^{1}$, Riffa Haviani Laluma ${ }^{2}$ \\ 1,2Jurusan Teknik Informatika, Fakultas Teknik \\ Universitas Sangga Buana YPKP \\ sofian.informatika@gmail.com,rhavani@gmail.com
}

\begin{abstract}
ABSTRAK
Tumor otak adalah salah satu penyakit yang paling mematikan yang menyerang manusia, tidak sedikit pria atau wanita di usia 20-30 yang mengidap penyakit ini. Untuk mendeteksi tumor otak pada seseorang, dokter menggunakan mesin MRI, karena hasil citra MRI terbukti memberikan hasil citra yang lebih baik dibandingkan dengan citra CT-Scan, namun terkadang hasil citra MRI sulit untuk dibedakan antara citra MRI otak tersebut memang mengidap tumor atau tidak, dikarenakan kontras yang dihasilkan seperti organ normal lainnya. Dengan metode Treshold, suatu citra dapat dipisahkan dengan objek lainnya dan metode GLCM digunakan untuk mengekstraksi ciri yang terkandung dalam citra tersebut. Lalu Metode KNN digunakan untuk klasifikasi hasil ciri suatu citra, dengan menggunakan $\mathrm{K}=3$. Pada penelitian ini digunakan Data Training sebanyak 20 data dan Data Testing sebanyak 10 data, maka dihasilkan akurasi sebesar 83.33\%, untuk MSE dan MAE masing-masing sebesar $16.6 \%$.
\end{abstract}

Kata Kunci: Citra MRI, Image Threshold, GLCM, KNN, Akurasi.

\section{PENDAHULUAN}

Otak adalah bagian terpenting dalam tubuh manusia yang berfungsi untuk mengendalikan seluruh sistem syaraf yang ada dalam tubuh manusia, fungsi otak akan terganggu jika otak tersebut terdapat tumor, baik tumor jinak (Benigna) atau tumor ganas (Maligna). Tumor otak adalah salah satu penyakit yang sangat mematikan bagi manusia, dan tumor otak dapat menyebabkan kematian bagi pria di usia 20 -30 tahun. Dan merupakan penyakit berbahaya kelima yang menyebabkan kematian bagi wanita di usia 20-30. Menurut International Agency for Research on cancer, lebih dari 126.000 orang di dunia setiap tahunnya mengidap penyakit tumor otak dan lebih dari
97.000 orang meninggal dunia. Pada tahap stadium awal, memang sangat sulit diketahui karena bentuk dan kontras dari hasil citra rongcent otak tidak begitu jelas, dan terkadang tumor tersebut mirip dengan jaringan normal didalam otak.

Magnetic Resonance Imaging (MRI) merupakan alat kedokteran yang berprinsip pada resonansi magnetic inti atom hydrogen. Dan merupakan alat diagnostik radiologi, MRI menghasilkan rekaman gambar dari tubuh atau organ manusia dengan menggunakan benda magnet. MRI diklaim sebagai alat pencitraan organ tubuh manusia dengan kualitas sangat baik, sehingga alat MRI banyak digunakan oleh para dokter. 
Untuk menterjemahkan hasil dari citra MRI, maka metode Gray Level Co-occurrence Matrix (GLCM) digunakan. GLCM adalah matriks yang menggambarkan dan merinci setiap unsur yang ada pada suatu citra. Dimana pada metode ini terdapat beberapa unsur citra seperti Kontras, Homogenitas, Energi, Korelasi dan Entropi.

Maka untuk mengolah hasil citra MRI ini digunakanlah Metode KNN sebagai metode utama dalam klasifikasi citra. Setiap Unsur citra memiliki kesamaan nilai jarak yang tidak terlalu jauh. Dimana Metode KNN menggunakan Jarak dari setiap $\mathrm{K}$ - Tetangga yang memiliki kemiripan hampir sama atau bahkan sama.

\section{TINJAUAN PUSTAKA}

1. Studi Literatur

Studi literatur adalah mencari referensi teori atau penelitian yang sesuai dengan kasus atau permasalahan yang ditemukan. Dimana pada penelitian ini peneliti mengumpulkan dan mempelajari penelitian yang serupa atau sejenis dengan judul yang diambil, baik dari jurnal nasional maupun internasional.

\section{Data}

Data yang digunakan dalam penelitian ini, menggunakan Data Publik yang tersedia di situs IEEE dimana data tersebut telah diuji dan dipublikasikan di situs tersebut.

\section{Pengolah Citra}

Pengolahan citra adalah salah satu proses untuk meningkatkan kualitas dari suatu citra. Secar umum computer dapat mengolah citra dalam bentuk citra biner, grayscale dan citra berwarna. Dimana proses pengolahan citra pada umumnya dilakukan beberapa tahap yaitu:

a. Akuisisi citra

Pengambilan data citra yang dilakukan dengan menggunakan berbagai media seperti kamera analog, kamera digital, handycamp, scanner dan sebagainya.

b. Peningkatan Kualitas Citra Pada tahap ini suatu citra ditingkatkan kualitasnya, dimana tahap ini bisa menjadi salah satu keberhasilan pada tahap pengolahan citra digital berikutnya.

c. Segmentasi Citra

Pada tahap ini bertujuan untuk memilih dan memisahkan suatu objek citra dari keseluruhan citra yang ada.

d. Ekstraksi Citra

Tahap terakhir dalam pengolahan citra, dimana tahap ini adalah sebagai penentuan dan akhir dari pengolahan citra.

\section{Gray Level Co-occurence Matrix}

GLCM merupakan salah satu metode yang efektif dalam proses ekstraksi Ciri suatu citra . dimana metode ini dapat melakukan klasifikasi dan identifikasi. Karena mampu memberikan informasi yang detail tentang suatu citra dalam hal tekstur.

Tahap ini membentuk GLCM 4 arah $\left(0^{\circ}\right.$, $45^{\circ}, 90^{\circ}$ dan $135^{\circ}$ ) dengan jarak $\mathrm{d}=1$ yang akan menentukan koordinat arah. Selanjutnya, dibentuk matriks kookurasi dengan cara menghitung frekuensi kemunculan pasangan nilai keabuan piksel referensi dan piksel 
tetangga pada jarak dan arah yang ditentukan. Kemudian menjumlahkan semua elemen untuk menghitung probabilitas setiap elemen dengan cara membagi setiap elemen GLCM dengan total semua elemen. Langkah terakhir yaitu menghitung ciri statistik GLCM. Ciri- ciri tersebut adalah:

\section{a. Energi}

Energi menyatakan ukuran konsentrasi pasangan dengan intensitas keabuan tertentu pada matriks. Nilai energi (E) dapat dihitung dengan persamaan(1):

$$
E=\sum_{i, j}\left(p(i, j)^{2}\right)
$$

b. Kontras

Kontras digunakan untuk mengukur frekuensi spasial dari citra dan perbedaan momen GLCM. Contrast merupakan ukuran keberadaan variasi aras keabuan pixel citra dihitung dengan cara sebagai berikut:

$$
\text { CONTRAST }=\sum_{n=1}^{L} n^{2}\left\{\sum_{|i-j|=n} \operatorname{GLCM}(i, j)\right\}
$$

\section{c. Korelasi (Correlation)}

Korelasi merupakan ukuran ketergantungan linier antar nilai aras keabuan dalam citra dihitung dengan menggunakan rumus:

$$
\text { CORRELATION }=\frac{\sum_{i=1}^{L} \sum_{j=1}^{L}\left(i-\mu_{i}^{\prime}\right)\left(j-\mu_{j}^{\prime}\right)(\operatorname{GLCM}(i, j))}{\sqrt{\sigma_{i}^{2} \sigma_{j}^{2}}}
$$

d. Homogenitas

$\begin{array}{lrr}\text { Homogenitas digunakan } & \text { untuk } \\ \text { mengukur kehomogenan } & \text { variasi }\end{array}$

intensitas citra. Nilai homogenitas $(\mathrm{H})$ dapat dihitung dengan persamaan:

$$
\operatorname{ASM}=\sum_{i=1}^{L} \sum_{j=1}^{L}\left(\operatorname{GLCM}(i, j)^{2}\right)
$$

e. Entropi

Entropi menyatakan ukuran ketidakteraturan aras keabuan didalam citra. Rumus untuk menghitung entropi yaitu:

$$
\text { ENTROPY }=-\sum_{i=1}^{L} \sum_{j=1}^{L}((\operatorname{GLCM}(i, j))(\log (\operatorname{GLCM}(i, j)))
$$

5. Algoritma K-Nearest Neighbor Classifier

K-Nearest Neighbor (KNN) adalah metode klasifikasi suatu objek berdasarkan data pembelajaran yang jaraknya paling dekat dengan objek tersebut. Metode ini bertujuan untuk mengklasifikasikan objek baru berdasarkan atribut dan training sample. Berikut tahapan pada KNN:

a. Menentukan nilai $\mathrm{K}$

b. Menyiapkan Data Training

c. Menyiapkan Data Testing

d. Menghitung Jarak Data Training Terhadap Data Testing dengan Menggunakan Rumus Euclidean Distance, dengan persamaan sebagai berikut:

$$
d_{i j}=\sqrt{\sum_{k=1}^{n}\left(x_{i k}-x_{j k}\right)^{2}}
$$

e. Mencari Nilai Terdekat sebanyak K

f. Mencari label modus terbanyak. 


\section{HASIL DAN PEMBAHASAN}

\section{Data Training}

Dibawah ini adalah Data Hasil Ekstraksi ciri Citra MRI yang telah dilakukan dari penelitian sebelumnya. Data training terdari 2 jenis tumor, yaitu: Tumor Benigna(Benign) dan Maligna (Malign).

Tabel 1: Data Training

\begin{tabular}{|c|c|c|c|c|c|}
\hline Contrast & Energy & $\begin{array}{l}\text { Corre- } \\
\text { lation }\end{array}$ & $\begin{array}{l}\text { Homo- } \\
\text { geneity }\end{array}$ & $\begin{array}{l}\text { Entro- } \\
\text { py }\end{array}$ & Result \\
\hline 19.9697 & 0.3535 & 0.4559 & 0.748 & 3.1137 & BENIGN \\
\hline 85.9331 & 976 & 0.0089 & 0.6881 & 3.4358 & BENIGN \\
\hline 320.2413 & 0.3008 & 0.5408 & 0.678 & 4.0389 & BENIGN \\
\hline 1.2921 & 0.0003 & 0 & 0.0007 & 0.0043 & BENIGN \\
\hline 1.7241 & 0.0003 & 0.0003 & 0.0007 & 0.004 & $\mathrm{GN}$ \\
\hline 4.5909 & 0.0002 & 0 & 0.0006 & 0.0045 & BENIGN \\
\hline & & 0.0004 & 0.0006 & 0.0044 & $\mathrm{GN}$ \\
\hline 5.9702 & 0.0002 & 0.0002 & 0.0006 & 0.0043 & BENIGN \\
\hline 7.3489 & 0.0002 & 0.0003 & 0.0005 & 0.0045 & BENIGN \\
\hline 9.9897 & 0.0002 & 0 & 0.0005 & 0.0046 & BENIGN \\
\hline 9.6659 & 0.3078 & 0.516 & 0.7174 & 3.7161 & MALIGN \\
\hline 15.7194 & 0.252 & -0.0816 & 0.6646 & 3.4083 & MALIGN \\
\hline 373.4352 & 0.2235 & 0.4172 & 0.5662 & 5.3947 & MALIGN \\
\hline 590.2047 & 0.1436 & -0.0809 & 0.7174 & 5.4892 & MALIGN \\
\hline 3.4852 & 0.0002 & 0.0003 & 0.0005 & 0.0057 & IGN \\
\hline 4.5499 & 0.0001 & -0.0001 & 0.0004 & 0.0062 & MALIGN \\
\hline 8.7649 & 0.0001 & 0.0003 & 0.0005 & 0.0056 & MALIGN \\
\hline 1.0561 & 0 & 0 & 0 & 0.0006 & MALIGN \\
\hline 8.7637 & 0.0001 & 0.0003 & 0.0004 & 0.0052 & MALIGN \\
\hline 1.5162 & 0 & 0 & 0 & 0.0005 & MALIGN \\
\hline
\end{tabular}

Sumber : Pauline John, 2012.

\section{Data Testing}

Data yang akan digunakan untuk Data Testing sebanyak 10 Citra MRI
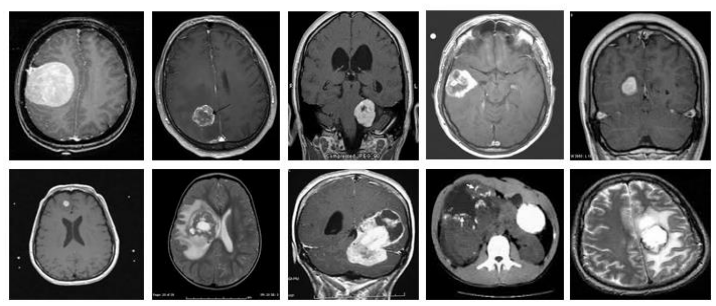

Sumber : Y-D. zhang dan L. Wu. 2012.

Gambar 1. Data Testing

\section{Alur Kerja Klasifikasi Citra MRI}

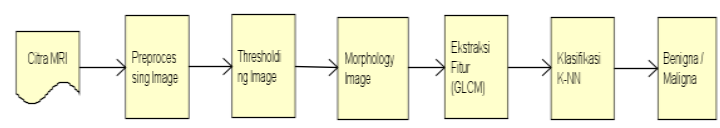

Gambar 2. Alur Kerja Klasifikasi
Proses klasifikasi dalam penelitian ini dimulai dari proses preprocessing image, dalam proses ini citra akan di resize dirubah kebentuk grayscale. Kemudian objek citra terpilih akan dipisahkan dari objek citra lainnya. Kemudian hasil citra akan di ekstraksi dan diambil nilai cirinya. Lalu hasil ekstraksi ciri akan digunakan sebagai penentu klasifikasi citra, apakah citra tersebut citra benigna atau maligna. Secara rinci dapat dilihat pada gambar dibawah:

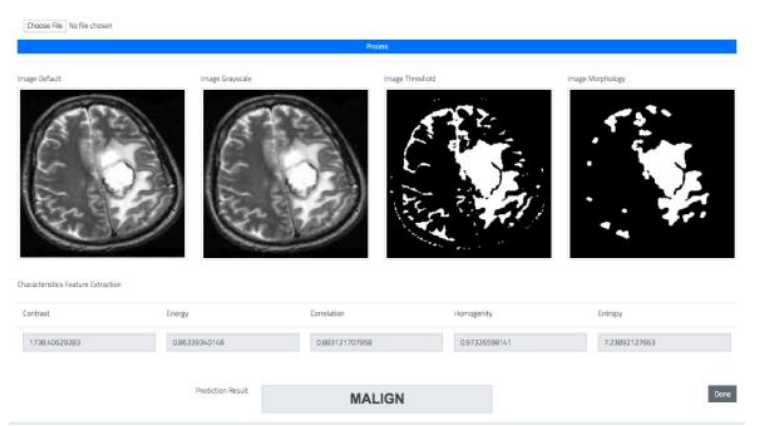

Gambar 3. Tampilan Klasifikasi Citra MRI

Dari gambar diatas dapat terlihat setiap citra yang telah diubah kedalam bentuk grayscale, threshold dan morphology. terlihat dibawah gambar, hasil ekstraksi ciri dari citra tersebut. Kemudian citra mri tersebut diprediksi sebagai citra Tumor Maligna.

Gambar 4. Grafik Akurasi, MSE dan MAE

Pada penelitian ini digunakan Data Training sebanyak 20 data dan Data Testing sebanyak 10 data dan nilai $\mathrm{K}$ yang digunakan 
adalah 3. Sehingga didapat tingkat akurasi sebesar $83.33 \%$ serta untuk nilai MSE sebesar $16.66 \%$ dan MAE sebesar $16.66 \%$

\section{KESIMPULAN}

Kesimpulan dari penelitian ini sebagai berikut:

1. Citra MRI dapat digunakan dalam memprediksi Tumor Otak

2. Metode Image Threshold cocok untuk segmentasi citra mri

3. Metode GLCM sangat bisa digunakan untuk klasifikasi Tumor Otak

4. Algoritma KNN bisa digunakan untuk mengklasifikasikan citra Tumor Otak

6. Akurasi dengan metode ini bagus sebesar: $\quad 83.33 \%$ namun bila dibandingkan dengan akurasi penelitian sebelumnya. Penelitian dengan metode KNN lebih kecil dan dengan nilai MAE sebesar: $16.66 \%$ dan nilai MSE sebesar: $16.66 \%$.

\section{DAFTAR PUSTAKA}

[1] Ayu Ambarwati, Rossi Passarella dan Sutarno. "Segmentasi Citra Digital Menggunakan Thresholding Otsu untuk Analisa Perbandingan Deteksi Tepi”. 2016 [online]. Available: http://seminar.ilkom.unsri.ac.id/index. php/ars/article/view/855. [accessed 27 Februari 2019].

[2] Marita Vinny, Nurhasanah dan Iklas Sanubary. "Identifikasi Tumor Otak Menggunakan Jaringan Syaraf Tiruan Propagasi Balik pada Citra CT-Scan Otak”. 2014 [online]. Available: http://jurnal.untan.ac.id/index.php/jpfu /article/view/22451/17839. [accessed 05 Ferbruari 2019].

[3] Muhammad Rivki dan Adam Mukharil Bachtiar. "Implementasi Algoritma K-
Nearest Neighbor dalam Pengklasifikasian Follower Twitter yang Menggunakan Bahasa Indonesia”. 2017 [online]. Available: https://jsi.cs.ui.ac.id/index.php/jsi/artic le/view/500/342. [accessed 16 Juli 2019].

[4] Pauline John. "Brain Tumor Classification Using Wavelet and Texture Based Neural Network". 2012 [online]. Available: https://www.ijser.org/researchpaper/Br ain-Tumor-Classification-UsingWavelet-and-Texture-Based-NeuralNetwork.pdf. [accessed 23 Februari 2019].

[5] Restu Widodo, Agus Wahyu Widodo dan Arry Supriyanto. "Pemanfaatan Ciri Gray Level Co-Occurrence Matrix (GLCM) Citra Buah Jeruk Keprok (Citrus reticulata Blanco) untuk Klasifikasi Mutu". 2018 [online]. Available: http://jptiik.ub.ac.id/index.php/jptiik/arti cle /download/3420/1336/. [accessed 06 Februari 2019].

[6] Rezky Rizaldi, Arik Kurniawati dan Cucun Very Angkoso. "Implementasi Metode Euclidean Distance untuk Rekomendasi Ukuran Pakaian Pada Aplikasi Ruang Ganti Virtual”. 2018 [online]. Available: http://jtiik.ub.ac.id/index.php/jtiik/artic le/view/592/pdf. [accessed 07 Agustus 2019].

[7] Rituja Mandhare, Jaya Nawale , Prabhanjan Kulkarni , Affan Ansari dan Smita Kakade "Brain Tumor Segmentation Using K-Means Clustering and Fuzzy C-Means Algorithms and Its Area Calculation and Disease Prediction Using NaiveBayes Algorithm " 2018 [online]. Available:

http://www.ijirset.com/upload/2018/ju ne/20_Brain_IEEE.pdf [accessed 05 Februari 2019].

[8] Sri Heranurweni,Budiani Desty ningtias dan Andi Kurniawan Nugroho "Klasifikasi Pola Image Pada Pasien Tumor Otak Berbasis Jaringan Syaraf Tiruan (Studi Kasus Penanganan Kuratif Pasien Tumor Otak)". 2018 
[online]. Available http://journals.usm.ac.id/index.php/ele ktrika/article/view/ $1169 / 766$ [accessed 16 Februari 2019]

[9] Widya Astuti Lastri dan Handayani T. "Klasifikasi MRI Otak Menggunakan Jaringan Syaraf Tiruan Berdasarkan Data Wavelet yang direduksi dengan NCMF". 2012 [online]. Available: http://jurnal.upnyk.ac.id/index.php/se mnasif /article/view/1056. [accessed 16 februari 2019].

[10] Y-D. Zhang dan L.Wu "An MR Brain Images Classifier Via Principal Component Analysis And Kernel Support Vector Machine". 2012 [online] Available: http://www.jpier.org/PIER/pier.php?pa per $=12061410$. [accessed 20 Februari 2019]. 